\title{
A identidade como recurso metonímico dos processos de patrimonialização
}

Identity as a metonymic resource of patrimonialization processes

L'identité en tant que recours métonymique des processus de patrimonialisation

Paulo Peixoto

\section{OpenEdition}

\section{Journals}

Edição electrónica

URL: http://journals.openedition.org/rccs/1056

DOI: $10.4000 /$ rccs. 1056

ISSN: 2182-7435

Editora

Centro de Estudos Sociais da Universidade de Coimbra

Edição impressa

Data de publição: 1 Dezembro 2004

Paginação: 183-204

ISSN: 0254-1106

Refêrencia eletrónica

Paulo Peixoto, «A identidade como recurso metonímico dos processos de patrimonialização »,

Revista Crítica de Ciências Sociais [Online], 70 | 2004, colocado online no dia 01 outubro 2012, criado a

19 abril 2019. URL : http://journals.openedition.org/rccs/1056 ; DOI : 10.4000/rccs.1056

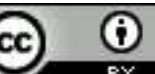




\title{
PAULO PEIXOTO
}

\section{A identidade como recurso metonímico dos processos de patrimonialização*}

\begin{abstract}
Os processos de patrimonialização sustentam-se de uma retórica que deifica a noção de identidade. Também os processos de construção identitária se ancoram, sublimando-a, na noção de património. Daqui resulta uma ambiguidade inextricável entre os dois termos. Porém, nem todo o património cria identidade, nem toda a identidade dá origem a um património. Esta constatação permite questionar o modo como os processos de construção identitária se socorrem, por vezes, de recursos aos quais atribuem um estatuto patrimonial. Mas permite igualmente atestar que os processos de patrimonialização nem sempre visam fins que tenham a ver com a preservação de uma identidade. Por colocar a tónica nos processos de patrimonialização e não nos processos de construção identitária, é esta segunda via analítica que este texto privilegia. A análise de processos ocorridos em Portugal permite ilustrar, através de alguns casos empíricos, o modo como a identidade se converte num recurso metonímico dos processos de patrimonialização.
\end{abstract}

\section{Duas faces da mesma moeda?}

A relação ambígua entre património e identidade permitiria que os termos do título deste texto se invertessem. Falaria, então, do património como recurso metonímico dos processos de identificação. A opção vertida no título resulta do facto de focalizar a análise nos processos de patrimonialização e não numa análise das identidades. Sublinho que o que está em causa na discussão que se segue não são, nem a noção de património, nem a noção de identidade, mas a análise de processos através dos quais certos bens, práticas ou objectos adquirem um estatuto formal de protecção e de exibição. O papel central que as noções de identidade e de património adquirem neste texto resulta do facto de eles se converterem em recursos retóricos desses mesmos processos.

Património e identidade aparecem frequentemente como termos de uma mesma equação. Um património faz prova da existência de uma determi-

\footnotetext{
* Texto elaborado no âmbito do projecto de investigação "Dinâmicas de recomposição sócio-económica dos centros históricos: o caso de Coimbra" (POCTI/SOC/60886/2004), financiado pela Fundação para a Ciência e a Tecnologia e executado pelo Centro de Estudos Sociais.
} 
nada identidade. Uma identidade insinua-se e justifica-se na medida em que se revela caucionada por um património. É com esta equação simplista que somos recorrentemente confrontados. Se a aceitarmos acriticamente, as verdadeiras razões da proliferação inaudita das estratégias de patrimonialização permanecerão latentes. O património presta-se a acções pedagógicas, turísticas, políticas, económicas e a experiências técnicas e sociais de ponta (Guillaume, 1980; Ashworth, 1994; Peixoto, 2003). A validação sumária dessa equação grosseira elide, por outro lado, que nem tudo que gera identidade pode ser encarado como património. Grande parte daquilo que distingue as identidades permanece num estatuto de não especificado e de não reconhecido (Howard, 2003: 147). Neste sentido, e no contexto do objecto aqui tratado, património e identidade apresentam-se como elementos de uma nova sintaxe do espaço urbano. $\mathrm{Na}$ estreita e ambígua relação que os une, os dois termos têm vindo a ser recodificados e exacerbados, constituindo-se como uma metalinguagem das políticas urbanas. Mais do que aquilo que aparentemente significam, e enquanto metalinguagens, património e identidade representam tudo o que é ameaçado por uma urbanização lancinante, inclusive aquilo que, muitas vezes, nunca se teve: o espaço público, a qualidade de vida, uma auto-estima e uma identificação incondicionais em relação ao local de residência, a cidade à escala humana. Enquanto elementos da metalinguagem da nova sintaxe do espaço urbano, património e identidade devem ser encarados como recursos retóricos das políticas urbanas, encerrando em si muitas das ideologias que sustentam essas políticas.

Enquanto termos da mesma equação, património e identidade são, recorrendo a uma linguagem matemática, duas incógnitas. Ou, pelo menos, não fazem parte de uma equação que possamos designar por linear. Enquanto ficções contemporâneas, património e identidade não assentam puramente numa relação ecológica simbiótica. Se, como é recorrente, assumirmos a simplicidade da equação ficamos, por um lado, perante uma concepção excessivamente essencialista de identidade (que elide o seu carácter construído, relacional e conflitual) e, por outro lado, somos confrontados com uma concepção de património que não deixa transparecer devidamente o seu carácter de ficção cultural ao mesmo tempo encantatória, selectiva e idealizadora.

A refuncionalização do passado que as políticas urbanas promovem adquire formas diversas. Oscilando entre a reactivação, a reinvenção e a idealização, os processos de patrimonialização manifestam-se quando uma consciência patrimonial e o património substituem uma identidade vivida e partilhada, ou quando uma identidade é branqueada, depurada ou imagi- 
nada. Mas o património não corresponde necessariamente à versão mais essencialista de uma identidade. Elementos da vida quotidiana, propositadamente concebidos para funcionarem como identificadores, não estão, muitas vezes, protegidos pela logística de conservação que define o espírito da indústria do património. Esses elementos são, no seu espírito, transitórios e só o risco do seu desaparecimento enquanto signos de uma identidade vivida e partilhada realça o seu estatuto patrimonial. Acresce que a relação entre o estatuto puramente identitário e o puramente patrimonial é com frequência conflitual, revelando-se esse conflito na concretização dos processos de patrimonialização.

Não negando a base simbiótica que pode unir identidade e património, aposto neste texto em evidenciar a relação enleada que ambos os termos mantêm entre si. Por isso, procurando olhar para aquilo que pretendem representar os objectos e os bens patrimonializados, e para as trajectórias que seguem até adquirirem um estatuto patrimonial, sustento a tese que a identidade é um recurso metonímico de processos de patrimonialização. É-o na medida em que se constitui como uma figura retórica e semântica que é mobilizada para conferir uma significação que traduza uma relação objectiva com objectos ou práticas resgatados pelos processos de patrimonialização para preencher novos usos sociais.

Ao privilegiar a análise da relação ambígua que identidade e património mantêm entre si, revelo que a formação de uma consciência patrimonial é um processo fortemente identitário. Mas descortino algo de mais importante. Porque, no modo como emerge e se desenvolve, qualquer acção de consciencialização patrimonial torna evidente que a função social crucial que pretende preencher é garantir a assimilação colectiva da mudança, funcionando como um estado de luto entre uma velha vida e uma nova vida. Nesse sentido, porque algo se perde irremediavelmente, as identidades não são imutáveis e, contrariamente aos objectivos de muitos processos de patrimonialização, o que importa realçar é o modo como a construção de patrimónios coloca em cena aquilo que a sociologia se habituou a designar por processos de identificação para dar conta do carácter parcial, partilhado e conflitual das identidades. Seguindo Maria Irene Ramalho (2001), a identidade é uma acção performativa e espectacularizada; uma representação necessária à transformação social. Diria que a identidade fornece metonimicamente recursos aos processos de patrimonialização para que a mudança seja colectivamente aceite, apropriada e superada. O carácter ficcional e figurado das identidades permite, como demonstram os casos empíricos mobilizados neste texto, que o invólucro seja tomado pelo conteúdo, a marca pelo produto, o concreto pelo abstracto e vice-versa, a matéria pelo objecto, 
a parte pelo todo, o artista pela obra, a causa pelo efeito. Este jogo representacional e cénico dos processos de patrimonialização não se concretiza, no plano da economia política das identidades, sem exclusões, sem dominações e sem exuberâncias (Mendes, 2001).

Para consolidar e exemplificar empiricamente o argumento que sustento socorro-me de cinco breves casos que, neste contexto, adquirem um valor ilustrativo. Em primeiro lugar, analiso um processo de tentativa de implantação de um sistema de videovigilância no centro histórico de Guimarães. Constato que, em nome de uma identidade imaginada, se constitui um processo de patrimonialização marcado por preocupações de disciplinamento social desenquadradas das práticas quotidianas. Em segundo lugar, aludo aos processos de coloração dos edifícios que são objecto de operações de requalificação nos centros históricos. $\mathrm{Na}$ sua essência, são processos de patrimonialização dominados pelas ideias e pelos ideais de purificação e de depuração. Conduzem a uma idealização do real, do espaço, da história, dos edifícios e das práticas que aí ocorrem, fazendo com que a função "artística" substitua a função social em que supostamente a identidade se baseia. Dou conta, em terceiro lugar, da elaboração de um tipo de material que pretende difundir normas e padrões de civilidade em espaços patrimonializados. Com isso viso revelar que a viabilização de um património assenta frequentemente em operações de branqueamento de certas características identitárias. Em quarto lugar, faço referência à reactivação de linhas-férreas abandonadas para a promoção de circuitos turísticos. O recurso a este exemplo permite mostrar duas tendências da relação de não linearidade entre património e identidade. Por um lado, revela que a refuncionalização que ocorre sob o signo da patrimonialização não se faz sem operações de "fascinação" que remetem para comunidades perdidas e imaginadas, revelando-se dessa forma o carácter construído e relacional das identidades. Por outro lado, a reactivação de objectos que tinham deixado de estar integrados nas práticas quotidianas tem efeitos perversos e evidencia, quando torna patentes as incompatibilidades entre os usos presentes e os usos antigos, o carácter conflitual de uma identidade que se transformou. Por fim, retenho um exemplo de uma operação de musealização in situ. É um caso que ilustra que a formação de uma consciência patrimonial nos confronta com a necessidade de empreender a assimilação colectiva da mudança, sendo que nesse processo se confessa o carácter mutável das identidades. Mas que revela também a tensão de uma identidade em transição entre a identidade que já não é vivida e aquela que ainda não teve tempo para poder funcionar sobretudo como uma identidade exibida. 


\section{O Big Brother nos centros históricos}

Porque recusaram os habitantes de Guimarães um sistema de videovigilância no centro histórico se isso supostamente lhes traria mais segurança? Ainda que os motivos dessa recusa não sejam aqui abordados na sua totalidade, esta questão permite discutir algumas razões sociais e políticas que se escondem por detrás das muitas acções de experimentalismo técnico aplicadas nos centros históricos através de uma panóplia de instrumentos e equipamentos especificamente concebidos ou adaptados para resolver problemas que aí existem. No caso concreto aqui analisado, trata-se de mostrar que o risco do sentimento de insegurança pode ser aproveitado e estimulado para exercer formas de controlo que aumentam de facto o risco de insegurança. Mas mais do que isso. Em situações onde não existe nem a insegurança nem um sentimento da mesma, como, grosso modo, é o caso do centro histórico de Guimarães, a tentativa de imposição de um sistema de videovigilância revela aquela que é uma das características mais marcantes das soluções experimentalistas que tomaram conta dos processos de patrimonialização: a ideia de que uma sociedade regulada e formatada é melhor para toda a gente.

Em Outubro de 1997, uma sessão da Assembleia Municipal de Guimarães terminou abruptamente quando o Presidente da edilidade decidiu abandoná-la extemporânea e vociferantemente, argumentando que o sistema de videovigilância que a Câmara Municipal pretendia instalar no centro histórico em nada afectava a privacidade dos cidadãos. A este argumento, esgrimido por alguns deputados municipais e partilhado por vários munícipes, o edil António Magalhães contrapunha a necessidade de implementar um sistema que permitisse proteger os monumentos históricos e os bens patrimoniais existentes no centro urbano. Não porque se estivesse perante sinais evidentes de vandalismo, ${ }^{1}$ mas porque seria conveniente garantir uma protecção adicional a um património que queria receber da UNESCO, como mais tarde viria a acontecer, o estatuto de património mundial.

\footnotetext{
${ }^{1}$ Embora a presença e a concentração de utilizadores de drogas na Praça de S. Tiago, junto à Praça da Oliveira, ocorra com alguma regularidade, essa presença não tem redundado em qualquer tipo de agressões ao património ou outras acções de vandalismo. Em relação a esta situação, a Câmara Municipal acabou por colocar um funcionário de vigilância ao local, numa evidente operação de higienização tão característica das acções experimentalistas. Estas operações de higienização, como veremos na discussão de um dos próximos casos, assumem, por vezes, contornos voluntaristas e contraproducentes. Em Guimarães, por iniciativa do vigilante destacado, recorreu-se ao derrame de lixívia (um produto que simboliza a pureza e a higiene) para impedir que os utilizadores de drogas fizessem uso dos bancos de pedra das praças e das arcadas durante largos períodos do dia, evidenciando-se esta iniciativa como simbolicamente reveladora de medidas de higienização social que estão a ocorrer nos centros históricos.
} 
No centro histórico de Guimarães predominam ainda os modos tradicionais de gestão dos principais riscos urbanos, baseados num urbanismo de proximidade, na vizinhança espacial, no interconhecimento, num certo espírito de colectividade e na existência de instituições próximas capazes de operar nos diversos domínios em que esses riscos se manifestam. Mas o facto de o centro histórico ser habitado por indivíduos tendencialmente idosos coloca em causa os modos tradicionais de gestão dos riscos urbanos e potencia riscos específicos de uma população com esse perfil. Acresce que o centro histórico de Guimarães, à semelhança de outros, tem vindo a conhecer o desenvolvimento de novas dinâmicas e sociabilidades. Entre estas podemos destacar as actividades nocturnas de lazer. Esta nova função dos centros históricos tem sido recorrentemente apontada como uma das principais responsáveis pelo clima de insegurança. O barulho proveniente de cafés, bares e discotecas que invadem os centros históricos, e que em Guimarães é particularmente visível na Praça de S. Tiago e imediações, provocam alguns conflitos com os residentes. Os desacatos, o vandalismo, o banditismo associados a um suposto consumo excessivo de álcool, assim como a presença de traficantes e consumidores de estupefacientes são algumas situações que contribuem, de acordo com as análises da imprensa, para o aumento do sentimento de insegurança entre os residentes e que configuram outras tantas situações de risco. Em casos extremos, os moradores dizem sentir-se reféns nas suas próprias casas e falam em clima de terror.

Não admira, por isso, que em espaços labirínticos e densos, como são os centros históricos, incluindo o de Guimarães, e onde novos sentimentos de risco despertam, a videovigilância apareça como uma solução que para muitos é óbvia, funcionando como equivalente funcional do panopticum de Bentham. A rigidez do espaço é assim contornada pela plasticidade de uma tecnologia que permite controlar sem ser vista (Foucault, 1977). Menos admira ainda que a solução da videovigilância tenha sido equacionada em Guimarães se tivermos em conta que os anos 90 do século XX são por excelência a década de expansão deste tipo de tecnologias. Elas são parte de uma panóplia de dispositivos que, na segunda metade do século XX, fazem a sua entrada nos centros urbanos alimentando impulsos de um experimentalismo social. O que verdadeiramente marca este experimentalismo é o desejo confessável de governar mais através da técnica e menos através de laços pessoais, substituindo-se a governação baseada na individualidade dos governantes e na dos governados pela impessoalidade de dispositivos técnicos.

O que é pertinente analisar é a disseminação rápida e abrangente destes dispositivos. Eles entram nos anos 70 no espaço urbano com o estatuto de 
equipamentos experimentais para ajudar a resolver os problemas do tráfego urbano. Nos anos 80, para assegurar a protecção dos indivíduos e dos bens, estes dispositivos tomam conta dos transportes colectivos, das zonas de comércio e de serviços e dos edifícios públicos. E nos anos 90 preparam uma nova etapa mais polémica quando é consumada a sua instalação na via pública (Vitalis, 1998).

Porém, em Guimarães, quando foi apresentada, a solução não foi pacificamente aceite. Como, de resto, pelas mesmas razões, não tem sido noutros locais. O que levou vários vimaranenses a contestar a videovigilância tem a ver com o facto de, neste caso, como noutros casos, a troco da eliminação de um sentimento de risco, ainda por cima exacerbado, poder estar a criar-se riscos concretos. Mas, se é verdade que todos aceitamos submeter-nos a um certo controlo no espaço público porque sabemos que uma certa autodisciplina é necessária à vida em sociedade e que ela só pode ser garantida através da existência de um controlo exterior, em que é que sermos filmados, muitas vezes sem o sabermos, altera o grau do controlo que poderemos estar dispostos a aceitar? $\mathrm{O}$ que muda em relação à mais pacífica aceitação da solicitação para apresentarmos um documento de identificação?

A recusa dos sistemas de videovigilância no espaço público tem tido menos a ver com a incerteza no que respeita ao destino e uso posterior das imagens captadas, que de si já é uma situação merecedora de preocupação, e muito mais a ver com duas características essenciais das imagens filmadas pelas câmaras. Em relação ao controlo que é feito através de documento de identificação, por exemplo, a imagem comporta duas grandes diferenças (Vitalis, 1998). Uma é que, enquanto o documento de identificação regista certa e determinada informação, a câmara de filmar regista tudo que entra no seu campo de visão. Uma imagem animada, ao contrário de um documento, é muito polissémica e pode tornar-se objecto de uma interpretação imediata. Ou seja, uma imagem animada suscita facilmente reacções primárias e interpretações sumárias. Por exemplo, a existência de um furto numa rua, não existindo imagens do furto, é imediatamente associada à presença filmada de utilizadores de drogas ou indivíduos de uma determinada etnia numa rua próxima. A outra é que, ao contrário de um documento, uma imagem animada não permite fazer uma distinção entre a realidade representada e a sua representação. Numa imagem animada o indivíduo não está representado, apresenta-se. Nesse sentido, sabendo-se filmados, os indivíduos tenderão a retrair os seus comportamentos no espaço público, na medida em que sabem de antemão que a imagem funciona como uma prova inequívoca em situações que possam envolvê-los. 
A questão que não pode deixar de ser colocada tem a ver com a vertente representacional da identidade local. Uma cidade pequena e pacata, sem indicadores alarmantes de vandalismo, na expectativa de ver a sua identidade transformada com a obtenção do estatuto de património mundial, pretende defender os elementos mais essencialistas dessa nova identidade: os seus monumentos históricos. Esta facilidade em essencializar (Mendes, 2001) revela que a percepção da mudança identitária é sentida como geradora de riscos. Este ímpeto de essencialização leva a que a parte seja facilmente tomada pelo todo e que a presença de eventuais marginais numa das praças centrais da cidade seja encarada como uma ameaça geral passível de uma reacção enérgica. Mas este caso evidencia pelo menos outra vertente em que a identidade se revela como recurso metonímico dos processos de patrimonialização. A videovigilância foi encarada como uma solução para um problema que só é um problema na medida em que a marca é tomada pelo produto ou o invólucro pelo conteúdo. O que justifica a videovigilância não são alterações nas dinâmicas internas da cidade, mas a eventual aquisição de uma etiqueta. Por outro lado, a identidade imaginada constitui-se como recurso metonímico dos processos de patrimonialização no sentido em que a causa é substituída pelo seu efeito. O novo rótulo identitário, desejado pelas políticas de patrimonialização em curso há anos, é encarado como a causa directa de eventuais riscos de vandalização do património. Como se essa distinção identitária fosse, por si só, geradora de actos de vandalismo. A reivindicação da necessidade de um sistema de videovigilância omite os efeitos das políticas de patrimonialização que levam a uma maior exposição dos monumentos a riscos de vandalização. Designadamente a maior pressão que a expansão das práticas de lazer (nomeadamente as nocturnas), motivada pela revalorização de um património, exerce sobre os monumentos históricos.

\section{Porto com pinta}

Em Novembro de 2001, a Câmara Municipal do Porto lançou, através da Agência de Modernização do Porto, uma experiência piloto destinada a valorizar a paisagem urbana. Na prática, tratou-se de pôr em marcha um programa de melhoria da imagem do espaço público assente na reabilitação de fachadas de edifícios públicos e privados, na substituição do mobiliário urbano e na preservação e disseminação de objectos de arte pública. O primeiro dos objectivos do programa acabou por ser aquele que ganhou maior visibilidade e é aquele que mais me interessa, tendo sido aprovada, nos primeiros dois meses de funcionamento, a recuperação de cerca de seis dezenas de fachadas no âmbito deste projecto. Interessa-me, sobretudo, 
por se revestir de um certo carácter inovador e experimentalista, na medida em que procurou concretizar as operações de reabilitação através de parcerias com empresas privadas. ${ }^{2}$ Em concreto, os termos da parceria estabelecem que as empresas envolvidas comparticipam nos custos, garantindo, em contrapartida, a colocação, isenta de taxas municipais, de painéis de publicidade nos andaimes das obras por um período de 3 a 4 meses. As parcerias das primeiras operações envolveram, por exemplo, a Unicer, as tintas Cin e o canal de televisão NTV, que procurou dar uma certa mediatização à iniciativa. ${ }^{3}$

Sintomático, para a abordagem que pretendo fazer deste caso, é que a Agência de Modernização do Porto apresente o projecto como sendo catalisador do reforço "dos valores paisagísticos que caracterizam a imagem da cidade do Porto, potenciando os valores cívicos que tornam as relações de cidadania mais fortes, justas, ricas e socialmente equilibradas". Destacando ainda como objectivos importantes da iniciativa a "promoção da participação da sociedade civil e do sector privado na manutenção e recuperação da paisagem e dos seus valores" (Apor, 2001). O Programa de valorização da paisagem urbana "Porto com pinta" não persegue apenas o reforço da qualidade do ambiente urbano, apostando, igualmente, na difusão de uma cultura de preservação e reabilitação do património edificado geradora de sentimentos de identificação à cidade. Nesse sentido, ainda que fazendo parte de edifícios privados, as fachadas prioritariamente seleccionadas são aquelas que têm um certo valor emblemático para a cidade, sendo, por isso, encaradas como um bem público passível de funcionar como signo identitário.

A assunção que os edifícios reabilitados são capazes de adquirir um valor emblemático e de gerar significados sociais, como se o visual fosse a condição fundadora de novas sociabilidades e de sentimentos identitários, tem um interesse que se estende para lá dos objectivos do "Porto com pinta". Diria, para problematizar a relação entre património e identidade, que se trata de um interesse assente em duas vertentes.

Por um lado, a assunção de que a paisagem urbana é crucial para gerar sentimentos de identificação norteia, em geral, os projectos de reabilitação urbana, dando origem a modelos que são reproduzidos em série e que

\footnotetext{
${ }^{2}$ Mas interessa-me igualmente, numa outra perspectiva que abordarei mais adiante, por reproduzir um modelo de reabilitação de circulação global, que, como muitas das políticas de intervenção patrimonial, teve lugar na cidade que concebeu originalmente grande parte destas iniciativas. Refiro-me concretamente a Barcelona e, mais propriamente, ao projecto "Barcelona, posa't guapa" inaugurado no início dos anos noventa.

3 O facto de se tratar da NTV não é despiciendo, dado estarmos perante um canal televisivo regionalista que se dirige especificamente àqueles que sentem o Porto e se identificam com a cidade.
} 
difundem valores de cidadania e de participação cívica. ${ }^{4} \mathrm{Na}$ prática e na retórica que o sustentam, o "Porto com pinta" inspira-se em Barcelona, cidade que concebeu e desenvolveu o modelo quando se iniciaram as operações de requalificação da zona histórica de Las Ramblas. Nessa altura, no final dos anos 1980, o professor da Escola Técnica Superior de Arquitectura de Barcelona, Jose Emilio Hernandez Cros, encarregado de recuperar a Casa Milà, de Gaudi, reuniu um grupo de profissionais activos e prosélitos que se empenhou em desenvolver sistemas de codificação cromática. Esta iniciativa levaria à consolidação de um projecto designado "Plano cromático para Barcelona" e ao aparecimento de um gabinete da cor, dirigido pelo arquitecto Joan Casadevall i Serra. Em Junho de 1997, procurando dar um novo impulso à iniciativa, é criado o Instituto Municipal da Paisagem Urbana e da Qualidade de Vida, que assumiu como filosofia fundadora e como acto inspirador as medidas que, em 1986, tinham presidido ao aparecimento da iniciativa "Barcelona posa't guapa". Assim, reiterando nos seus estatutos os objectivos que o "Porto com pinta" reproduz, e apostando em operacionalizar os conceitos de "paisagem urbana" e de "qualidade de vida", este Instituto assume estatutariamente e de forma explícita o objectivo de "promover Barcelona e o seu modelo de transformação urbana como referente para as restantes cidades do mundo" (IMPUQV, 2003).

Por outro lado, a segunda vertente em que se torna interessante analisar os pressupostos deste modelo para problematizar a relação entre património e identidade já não tem a ver especificamente com a globalização do modelo, mas sim com o facto de ele representar e traduzir o triunfo de uma concepção de património e de identidade sobre uma outra que lhe é oposta. Os primeiros movimentos conservacionistas preocupam-se essencialmente com proteger o património monumental e, em casos muito pontuais, o espaço imediato que os envolve (Choay, 1992). Haussmann, na revolução urbanística que empreende em Paris na segunda metade do século XIX, simboliza a aplicação desta filosofia conservacionista (Giedion, 1990). Só mais tarde, nos anos 1930, nos círculos culturais italianos, e particularmente devido às intervenções do arquitecto Giovannoni, se começa a abandonar a

\footnotetext{
${ }^{4}$ Noutro lugar, trato este fenómeno como um processo de benchmarking urbano (Peixoto, 2003).

5 Em concreto, a Câmara Municipal de Barcelona foi a responsável pela iniciativa que começou a ser concebida em 1985. A sua concretização quase imediata levou à mobilização de académicos, de associações profissionais de arquitectos e engenheiros, da Câmara do comércio, de sindicatos e da Igreja. A paleta de cores genuínas e autênticas que resultou do "Plano cromático para Barcelona", bem como a fundamentação teórica que a sustenta, depressa se reproduziram nos fora internacionais de arquitectura e urbanismo, impregnando não só os discursos técnicos mas também a prática profissional. A isto não é alheio o facto de o próprio IMPUQV se ter empenhado activamente na exportação do modelo cromático.
} 
prática de conservação individual de edifícios para se equacionar o lugar dos centros históricos no conjunto urbano de que fazem parte (Giovannoni, 1998). No início dos anos 1960, com a promulgação da lei Malraux em França (1962), fixam-se princípios de intervenção nos centros históricos baseados em planos de salvaguarda que, apontando para a conservação e restauração de sectores bem delimitados do espaço urbano, começam rapidamente a ser mimetizados noutros locais. A aplicação dos instrumentos e procedimentos da lei Malraux viria a estar na origem de processos de nobilitação ${ }^{6}$ urbana e, não obstante muitas das críticas que suscitaram por porem em causa a identidade do lugar (Ostrowski, 1976), esses procedimentos continuam hoje a ser aplicados. ${ }^{7}$ A partir dos anos 1980 , justamente quando Barcelona começa a moldar muitas das operações urbanísticas hoje em voga, impõe-se uma nova filosofia de planeamento. As linhas de orientação desta nova filosofia são dominadas pela ideia de reabilitação e de requalificação da cidade histórica e tradicional. Na origem desta nova orientação encontra-se a noção de "projecto urbano" que, de um modo muito claro nos anos 1990, ganha forma, no contexto de um processo de estetização urbana, através de noções que fazem moda: planeamento estratégico, cidade sustentável, espaço público, cidadania activa, qualidade de vida, cultura urbana, qualidade total, paisagem ambiental e patrimonial, identidade local, etc. O "projecto urbano", voltado para um urbanismo intensivo, visa essencialmente a concepção de espaços que fomentem uma pluralidade de usos. Esta pluralidade é a base da dinâmica desses espaços e é vista como o ingrediente que estimula a sua apropriação social por via do fomento de experiências identitárias e estetizantes. Assim, a política de requalificação de que o "Porto com pinta" se faz eco aposta no desenvolvimento de lugares de urbanidade que propiciem a reflexividade, a emergência de novos valores e sociabilidades, a criação de um espaço cénico de fruição estética e sensível e a afirmação de uma identidade caracterizada pelo espírito de lugar.

\footnotetext{
${ }^{6}$ A nobilitação, ou gentrification (termo inglês correntemente utilizado na gíria da reabilitação urbana), dá conta da substituição da população residente por outra de estratos sociais mais elevados na sequência de processos de conservação e de restauro de determinado espaço urbano.

7 Uma das reacções mais conhecidas e que se desenvolveu como modelo destinado a ser exportado teve origem na aplicação do Plano de recuperação do centro histórico de Bolonha (1969). O Plano para a edificação económica e popular nas zonas históricas, o projecto Colina de Bolonha, o Plano Intercomunal, a adopção de medidas de descentralização dos serviços públicos (Mora, 1993) fazem, juntamente com programas mais recentes (como, por exemplo, a adopção de programas de qualidade total em matéria de serviços prestados aos residentes), com que as experiências da cidade italiana sejam recorrentemente utilizadas como modelos das operações que visam recuperar conjuntos urbanos históricos sem que seja posta em causa a sua matriz identitária.
} 
Estas duas vertentes inerentes às filosofias vigentes de requalificação urbana - a reprodução de modelos de intervenção e a concepção de que todas as características e elementos dos centros históricos se constituem como factores patrimoniais e identitários -, sendo por vezes contraditórias, permitem-me interpelar as noções de património e de identidade.

A codificação cromática operacionalizada em Barcelona tem vindo progressivamente a disseminar-se graças aos arquitectos e é particularmente visível nas operações de requalificação urbana que têm sido efectuadas nos centros históricos (Costa, 1999). Essa verdadeira missão arquitectónica transporta consigo uma retórica de recuperação das cores originais e autênticas. Retórica e prática que, motivadas por rasgos artísticos, estéticos e depuradores que visam produzir exemplaridade e fascinação à luz de um modelo, nos levam a questionar se não estamos perante uma identidade e uma autenticidade encenadas (MacCannell, 1973).

Acresce que os centros históricos reabilitados funcionam como uma espécie de figuração da realidade, dado que o seu esplendor e a qualidade urbanística dos seus espaços, as cores garridas das fachadas recuperadas, frequentemente contrastando com o resto da cidade que os envolve, os tornam uma espécie de obra de arte que representa uma ideia abstracta de qualidade de vida que os residentes não experienciam e com a qual não se identificam. Neste âmbito, funcionam mais como imagem metonímica da cidade, convidando a tomar a parte, ordenada e embelezada, pelo todo. Estão, por isso, mais orientados para funcionar como cartão de visita das cidades (como marca) e menos como espaço onde uma identidade vivida e partilhada se desenvolve (o produto). Nas suas cores garridas, as fachadas dos centros históricos são um resultado de políticas de patrimonialização que se alimentam de uma identidade depurada e exacerbada em que, metonimicamente, o abstracto e o concerto se confundem e a matéria (tinta) se substitui ao objecto (residência).

\section{Aprender a saber viver}

A cidade do Porto é conhecida pela sua identidade granítica e peculiar, consolidada à volta dos seus bairros históricos, nomeadamente a Sé, Miragaia, Vitória e S. Nicolau. É também, em Portugal, um dos raros exemplos que permite dar conta de um trabalho mais ou menos sistemático de reabilitação urbana de um centro histórico ao longo de décadas, tendo esse processo atingido o seu auge em 1995 quando a Unesco atribuiu ao centro histórico do Porto o estatuto de património mundial.

O Manual do morador da zona bistórica do Porto (FDZHP, 1998) é seleccionado no âmbito deste texto enquanto objecto integrado num processo 
de sustentação e de consolidação de um património. ${ }^{8}$ Não pondo em causa a importância dos conselhos utilitários que veicula, fixo-me nas ideologias que divulga. Ele exemplifica, no limite, um caso de disciplinamento e de higienização de comportamentos que dá conta do carácter construído, relacional e conflitual das identidades. Por outro lado, enquanto instrumento de formatação de comportamentos que procura elevar os níveis de urbanidade e fomentar outros padrões de cultura urbana, o manual está ajustado às casas recuperadas pela instituição que o elaborou, sendo, no entanto, questionável que a maior parte dos princípios que difunde e das ideologias que veicula se apliquem à larga maioria das casas da zona histórica do Porto, demasiado degradadas para se enquadrarem no nível de gestão que o manual convida a desenvolver. E o mesmo pode dizer-se para muitos dos residentes, que, vivendo em condições precárias, são forçados a gerir a suas vidas quotidianas com base num improviso não compatível com a racionalidade e o grau de programação que o manual difunde.

Essa ideologia e os impulsos de urbanidade subjacentes ao manual são, desde logo, visíveis na sua apresentação, quando se afirma que "depois de tanto esforço para ver confirmada esta legítima aspiração [de ver o Porto reconhecido como património mundial], cada um de nós tem o dever de dar o seu melhor para mostrar que sabe viver num lugar muito especial e numa cidade única como é o Porto". Não deixa de ser irónico registar que aqueles que, vivendo lá, conferiram à zona histórica um carácter sui generis que lhe permitiu ser reconhecida pela Unesco sejam agora convidados a aprender a "saber viver" nesse lugar.

Há, por outro lado, reminiscências de um experimentalismo técnico neste instrumento de difusão de padrões de urbanidade. "Uma casa pode ser comparada a uma máquina. Se todas as peças funcionarem a máquina trabalha bem, mas se uma das peças falhar, a máquina baixa o rendimento, ou pára. Por isso, cada pequena função deve ser bem planeada." Este princípio, que coloca os indivíduos como elementos de uma engrenagem, não tem apenas o objectivo implícito de promover uma nova socialidade que fomente o prazer comunitário de levar uma vida em comum dentro de regras da boa convivência e da civilidade. Visa também, de certo modo, naquele que é um dos objectivos das acções experimentalistas, criar protótipos e modelos

\footnotetext{
${ }^{8}$ Este tipo de publicação não é um caso isolado, havendo outras publicações do género, inclusive noutros países, igualmente destinadas a definir padrões de urbanidade. Entre nós, assumindo claros objectivos pedagógicos, temos, entre outros, o Manual do morador editado pelo Departamento Municipal da Habitação da Câmara Municipal de Odivelas; o Manual do morador editado pelo pelouro de Acção Social da Câmara Municipal de Aveiro. Também não é, por outro lado, um caso recente, já que, desde há muito, em contextos de educação das classes populares, foram produzidas publicações semelhantes para disciplinar e higienizar comportamentos.
} 
identitários, na medida em que procura converter esses indivíduos em exemplares produzidos por um projecto de requalificação. Ao receberem uma casa reabilitada e ao viverem num espaço requalificado, ainda que apenas por um estatuto patrimonial, os indivíduos são encarados como cobaias de experiências que visam testar e desenvolver novos modos de vida e uma nova identidade. Nesse sentido, no complexo mercado da requalificação urbana, onde as casas reabilitadas são sempre muito menos que aqueles que pretendem obtê-las, é suposto que os indivíduos que tiveram essa sorte se constituam como modelos passíveis de serem copiados e reproduzidos no âmbito de processos de requalificação semelhantes. É por isso que, de certa forma, esses indivíduos são convidados a deixar de ser o que eram.

As ideologias dos projectos de requalificação urbana assumem frequentemente objectivos declarados de higienização dos hábitos das classes populares. O manual analisado faz transparecê-los quando, por exemplo, afirma que "a higiene e a manutenção da casa é uma garantia de conforto e de saúde. A limpeza periódica da habitação é indispensável, mas não substitui uma limpeza mais aprofundada de vez em quando. Normalmente concentram-se em determinados pontos, fungos e bactérias que não são visíveis e que provocam alergias, problemas respiratórios e outras doenças. Por isso, o pó deve ser retirado regularmente e o chão deve estar sempre limpo." Estes objectivos de higienização, quase sempre motivados por tentativas de imposição dos padrões de urbanidade das classes médias, revelam que os projectos de requalificação fazem com muita frequência tábua rasa das situações de partida. E se é importante ouvir e ter em conta os padrões de vida dos residentes, não é só porque quase tudo daquilo que por eles é dito e feito quase nunca resiste a um projecto de requalificação. É também porque, muitas vezes, a realidade acaba por se impor aos projectos e aos seus objectivos fazendo-os ruir.

Este objecto de consolidação de um património dá, como dissemos, conta do carácter construído, relacional e conflitual das identidades. Construído na medida em que, afinal, a identidade que foi reconhecida como património precisa agora de ser, de algum modo, fabricada e refinada, pois quem lá vive tem de aprender a viver lá de outra forma. Assim, a identidade pode ser perigosa para o património. Mas como seria uma heresia matá-lo, porque esse património não foi fácil de conseguir, a condição de sobrevivência desse património é a morte de uma identidade. Relacional porque apela ao desenvolvimento de sentimentos de identificação numa lógica comunitária e positivamente valorizada: "cada rua, cada beco, cada casa, cada pedra testemunha histórias e guarda segredos que se perdem no tempo. Para todos nós que aqui moramos e trabalhamos, isso é motivo de grande orgulho [...]”. 
"Os vizinhos fazem parte do ambiente onde vivemos e, por isso, são muito importantes na vida quotidiana. São eles que se encontram mais perto de nós quando precisamos da ajuda de alguém. [...] Nunca é tarde para cuidar do bom relacionamento com os vizinhos. Se assim o fizer, verá que ao fim de algum tempo se sentirá mais seguro e orgulhoso." Conflitual não só porque coloca os indivíduos perante uma dupla identidade, entre o que já não podem ser e o que ainda não sabem ser, mas também porque o apelo à identificação é ao mesmo tempo uma forma de reforçar a alteridade; de dar conta da presença do estranho, daqueles que por não sentirem da mesma forma que os residentes o património como seu podem constituir uma ameaça.

\section{O Douro a todo o vapor}

A reactivação de linhas-férreas e de redes de eléctricos é um fenómeno que está em voga entre nós no âmbito de consolidação de um património ferroviário. A título de exemplo, registo o regresso dos antigos eléctricos à cidade do Porto, "recuperados e adaptados às actuais normas de segurança e de conforto, mas mantendo a traça e pintura originais" (Público, 2002a), para preencher uma função eminentemente lúdica. Designadamente para transportar congressistas do Palácio da Bolsa ou da Alfândega para o Largo do Viriato ou para o Campo Alegre, bem como para permitir passeios à beira-rio e apreciar uma moldura consagrada como património mundial. Posso destacar também, para ilustrar este fenómeno e introduzir o argumento que sustento e desenvolvo no próximo ponto deste texto, a tentativa de fazer regressar aos carris, 23 anos depois de ter sido interrompido, o eléctrico que, desde 1904, fez a ligação entre a Ribeira de Sintra e a Praia das Maçãs. Este projecto apresentou-se para os eleitos locais, a partir do início dos anos 1990, como uma das apostas para reforçar a atractividade de Sintra que, na altura, estava empenhada em obter o estatuto de património mundial, atribuído pela Unesco em 1995. A vontade em querer refuncionalizar um antigo meio de transporte acabou mesmo por se tornar um pequeno pesadelo para a Câmara Municipal, já que o projecto conheceu inúmeros contratempos desde que, precisamente no ano em que viria a obter o estatuto de património mundial, a Presidente da Câmara convidou a comunicação social para uma viagem de apresentação de reactivação da linha. ${ }^{9}$

\footnotetext{
9 Não explorando intensivamente este caso, registamos apenas que o eléctrico de Sintra teve o seu período áureo até aos anos 1930. Quando os automóveis e os autocarros começaram a constituir-se como alternativas, e a exploração da linha começou a ser pouco rentável, a sua degradação foi-se acentuando. Pautada por uma decadência gradual, que fez com que na altura da interrupção a circulação dos eléctricos se limitasse já aos meses de Verão, a linha foi fechando troço após troço
} 
A falta de interesse da população e dos turistas pelo novo património, motivada pelo elevado custo das passagens e pelo tempo excessivo da viagem, levantam questões interessantes relativas às expectativas dos projectos de patrimonialização que pretendem reactivar usos passados e identidades perdidas relativamente recentes. Dessas questões darei conta no próximo ponto deste texto.

O caso a que pretendo conferir maior destaque relativamente a este fenómeno da recuperação das linhas-férreas procura ilustrar o modo como o património, para poder consolidar-se como tal, tem necessidade de reinventar uma identidade, razão pela qual o património nem sempre convive bem com características actuais que dão forma a identidades.

A partir de 2000, e não será irrelevante recordar que o centro histórico do Porto tinha sido reconhecido património mundial em 1996 e que o Alto Douro Vinhateiro viria a sê-lo em 2001, a CP (Caminhos de Ferro Portugueses) lançou uma campanha designada "Comboios históricos do Douro" (Cardoso, 2002). Para esse efeito, a CP recuperou locomotivas a vapor dos anos 1920 e máquinas a diesel dos anos 1960 e 1970. A estas locomotivas juntam-se 5 carruagens históricas construídas entre 1908 e 1934. Todo este material de circulação ferroviária foi recuperado ao mais ínfimo pormenor na sua traça original, de modo a permitir recriar um ambiente a lembrar as viagens dos inícios do século XX. Estas composições circulam nas linhas do Douro e Corgo, entre os meses de Março e Outubro, e, juntamente com a oferta disponibilizada pela Spidouro (Sociedade de Promoção de Empresas e Investimentos do Douro e Trás-os-Montes, que promove cruzeiros no Douro, produtos regionais e grupos e eventos culturais), dão forma a um produto turístico sui generis, especialmente destinado a agências de viagens, operadores turísticos e empresas que pretendam organizar viagens sócio-recreativas. A oferta, à medida do cliente, tem vindo a ser entrosada com programas de animação local existentes, podendo incluir animação à moda do início do século XX e produtos regionais dos "bons velhos tempos". Para amenizar uma viagem feita a $30 \mathrm{~km}$ à hora, a animação é feita no interior do próprio comboio através da banda "Bagos Maduros" e de uma equipa de "hospedeiros" trajados à moda do início do século XX.

Estes comboios transportaram 2600 passageiros no ano 2000 e 4500 em 2001. Em 2003 o número de passageiros transportados aproximou-se dos 10 000, sendo que uma larga maioria deles (cerca de 90\%) são de naciona-

para, em 1974, fazer uma circulação muito restrita entre o Banzão e a Praia das Maçãs. O renovado interesse a partir dos anos 1990 ficou esmorecido quando a Stage Coach, que, com a privatização da Rodoviária Nacional, tinha obtido a concessão da linha, constando os elevados custos de manutenção e a fraca rentabilidade, deixou a Câmara de Sintra a gerir o projecto sozinha. 
lidade portuguesa. O sucesso da iniciativa levou a CP a recuperar mais carruagens do que inicialmente tinha sido programado, a revelar o seu interesse em fazer circular os comboios históricos noutras linhas e a investir em campanhas de promoção e de marketing. A este propósito regista-se a promoção feita através de vídeos nos aviões da TAP de modo a tentar captar turistas estrangeiros. Em 2004 a CP, através de uma parceria com o Instituto dos Vinhos do Douro e do Porto, recuperou e expôs na Gare do Oriente em Lisboa novas carruagens pintadas com os logótipos de empresas do vinho do Porto. A CP empenhou-se também na criação de uma Fundação dos comboios históricos do Douro, capaz de envolver mais activamente os agentes turísticos e as Câmaras Municipais, de modo a consolidar esta oferta turística com uma animação mais atractiva e vernácula que dê a conhecer a verdadeira identidade da região. Assim, para Setembro, passou a programar-se o "comboio das vindimas", que conta com um programa de animação específica alusivo à temática. Relativamente a este conjunto de acções, diria que ele faz parte de uma logística destinada a exacerbar e a encantar a importância histórica dos comboios a vapor no desenvolvimento da região vinícola do Douro. O produto mais emblemático de um lugar é usado como recurso, substituindo-se metonimicamente ao próprio lugar, para fomentar o imaginário e favorecer políticas de patrimonialização de bens e produtos menos prestigiados.

Tudo isto não se faz sem que o "lado negro da nostalgia" (Público, 2002b) se manifeste. Este património, também ele um elemento de valorização da paisagem vinhateira, tem-se afinal revelado nefasto para a realidade presente dessa paisagem devido aos inúmeros incêndios que tem causado e à destruição de hectares de vinha e olival da zona classificada como património mundial. $\mathrm{O}$ facto de ser equacionado o cancelamento deste serviço (Osório, 2002) representa, de certo modo, o reconhecimento da transformação das identidades, que tornam anacrónicas certas funções e bens, e a dificuldade que determinadas formas de exibição de patrimónios, ao serem convocados para uma segunda vida, conhecem quanto tentam impor-se em contextos identitários que já não são os seus porque deixaram de estar integrados nas práticas quotidianas. Esta possibilidade de cancelamento não é alheia ao facto de esse anacronismo se manifestar de outra forma que tem a ver com os elevados custos de manutenção e de viabilização deste património, o que o torna pouco atractivo para os operadores turísticos que dispõem de outros meios alternativos para dar a conhecer a paisagem vinhateira do Douro. Da Régua ao Pinhão, uma locomotiva a vapor gasta uma tonelada de carvão, que, devido ao encerramento das minas do Pejão, vem agora de paragens mais distantes (México e Polónia). 
Este património, promovendo uma certa folclorização, acaba, como tantos outros, por se converter em palco de manifestação de redes de simulacros desligados da vida quotidiana e dos contextos identitários em que se manifesta. $\mathrm{O}$ valor patrimonial dos comboios históricos é utilizado para difundir uma atmosfera de prazer e de encanto que, oferecendo experiências à moda antiga, procura transcender o ordinário e produzir permanentemente "exemplaridade" e "fascinação". Põe, contudo, a nu o facto de o reconhecimento e a viabilização de um qualquer bem como património conviver, com frequência, mal com as características actuais do contexto em que ocorre (Frias e Peixoto, 2002).

\section{Confiança no passado}

Em Agosto de 2001, a Tipografia-Museu Confiança foi inaugurada com alguma pompa na presença dos representantes máximos da edilidade lisboeta. Tratava-se de reabrir uma pequena oficina situada na Rua da Rosa em pleno Bairro Alto, local que tinha sido o centro do jornalismo e da impressão na capital portuguesa. O projecto, da responsabilidade do Museu Nacional da Imprensa, tinha por objectivo recuperar um antigo espaço das artes gráficas tradicionais e realçar o estatuto patrimonial da actividade de imprensa, contando para tal com o apoio e o empenho da Câmara Municipal de Lisboa.

Uma certa indefinição de estratégias em relação à utilização prioritária do espaço, com a Câmara Municipal de Lisboa a defender a vertente museológica e o Museu Nacional da Imprensa a optar por colocar em funcionamento um estabelecimento comercial vocacionado para vender "os seus serviços a clientes interessados em trabalhos de impressão feitos à moda antiga" (Lopes, 2001), parece ter-se notado logo desde início. Mas não foi por isso que o projecto encalhou, já que, nos dois meses de funcionamento, acabou por preencher ambas as funções, recebendo inclusive visitas de estudo de alunos do ensino básico. O director da entidade responsável explicou na altura que a situação de encerramento seria temporária (idem, 2001). Para tal bastaria pôr em funcionamento os planeados cursos de formação de tipógrafos, de modo a dispor de funcionários capazes de trabalhar com a arte em causa, dado que os dois empregados da tipografia, antigos operários da casa já reformados, tendo uma certa idade e necessitando recorrentemente de ir ao médico, não podiam assegurar o normal funcionamento da oficina tal como tinha sido previsto.

Para a análise que pretendo fazer do caso resta acrescentar que a tipografia se encontrava pronta para receber encomendas, nomeadamente para a produção de materiais impressos de acordo com os processos ditos artesa- 
nais. Supostamente, existiam algumas encomendas de cartões de visita e facturas e o próprio Museu Nacional da Imprensa previa produzir uma boa parte dos seus materiais de divulgação na oficina. Este projecto sugestivo, "capaz de suscitar a atenção das pessoas", apresentava-se como singular não só em Portugal mas também na Europa. Porém, como o próprio director do Museu admitiu ao Público (Lopes, 2001), as encomendas para a produção de material impresso à moda antiga não só eram escassas como, quando existiam, eram muito frequentemente recusadas por dificuldades de cumprimento dos prazos de entrega. Em declarações ao mesmo jornal, um dos tipógrafos declarou, no entanto, que "depois de 42 anos a trabalhar na Tipografia Confiança não resistiu quando foi convidado a voltar à antiga oficina", reconhecendo embora que o tenha feito "mais para pôr as máquinas a trabalhar do que propriamente para fazer as impressões". Porque, na sua perspectiva, "quando esta casa fechou, os clientes encontraram outros sítios onde fazer as suas impressões. Agora estão contentes com o trabalho que lhes fazem e já não querem voltar a encomendar-nos a nós."

Este caso, relatando uma experiência globalizada de musealização in situ de um património industrial, revela a preocupação em revestir um modelo massificado de factores culturais diferenciadores que permitam apresentar a experiência como singular. Concretamente, trata-se de reactivar um passado recente, recuperando não só um contexto produtivo mas também os próprios actores. Mas trata-se igualmente de idealizar esse passado através de uma invenção cultural que procura refuncionalizar algo que se perdeu conferindo-lhe uma segunda vida a partir da valorização de critérios estéticos. Estamos, nestes casos, perante episódios de radicalização da diferença (Fortuna, 1999), que se revela num certo carácter experimentalista movido pela busca da característica mais original e única.

O facto de se tratar de um passado tão presente que permite recuperar os próprios actores desse passado é um factor importante. Ele revela que as tentativas de formação de consciências patrimoniais destinadas a conferir singularidade ocorrem cada vez mais à revelia do princípio de que um certo grau de inércia, baseado na ideia de que é preciso morrer para nascer de novo como produto estético que remete para "os velhos tempos", se afigura como fundamental. Nomeadamente, para conferir o valor simbólico capaz de garantir que os fenómenos reactivados possam afirmar-se como patrimónios consumíveis. Ou seja, não é despiciendo registar a boa vontade cultural que preside a certos projectos experimentalistas de patrimonialização. Neste caso, essa boa vontade baseia-se na presunção de que uma forma de produção artesanal recentemente desaparecida gerará a sua procura porque existem consumidores ávidos e saudosos de produtos à moda antiga. 
Não tão antigos, porém, que não permitam compreender que os contextos experimentais de patrimonialização não são isoláveis das dinâmicas sociais em que se baseiam. E que, por isso, aquilo que levou os clientes a afastarem-se da oficina (e ao fecho desta) não será certamente o que os fará lá regressar. O risco deste tipo de acções experimentalistas reside no facto de elas se alimentarem de passados tão presentes, e por vezes indesejados, que se arriscam a não ter qualquer futuro.

A identidade que este projecto concreto de patrimonialização visa utilizar enquanto recurso metonímico permite dar conta da tensão entre os antigos e os novos usos de bens e práticas sociais em constante mutação. Este caso revela que a criação de uma consciência patrimonial nos obriga a reconhecer o carácter mutável das identidades. A reconceptualização de um passado industrial (a Tipografia Confiança simboliza aqui a indústria da imprensa) não pode elidir que os operários e os consumidores da Tipografia Confiança actuavam como agentes de conservação de uma função económica, daquilo que a dada altura se quer chamar património, quando utilizavam a tipografia como prestador de serviços que eram socialmente úteis, quer para quem os produzia, quer para quem os consumia.

\section{O passado ainda não acabou}

Frequentemente, é necessário recordar aos prosélitos do património que o passado ainda não acabou. Sobretudo quando estamos perante tentativas de conferir um estatuto patrimonial a identidades vividas que potenciam o risco de uma possível vingança dessas identidades, hipotecando, assim, a afirmação de um qualquer património. As tentativas de compatibilização entre identidades vividas e estatutos patrimoniais são geradoras de episódios por vezes caricatos. A noção de património remete para a ideia de bens comuns que, perdendo as suas funcionalidades, deixaram de estar integrados nas práticas económicas e sociais quotidianas. Ela evoca uma necessidade de inscrever na memória colectiva algo que corre o risco de se perder. Neste contexto, a "descoberta" de um património corresponde ao anúncio da morte de uma identidade. Querer manter vivas nas práticas quotidianas características e funções identitárias quando elas já não são social e economicamente úteis é tentar combater a inelutável assimilação colectiva da mudança inerente aos processos de transformação identitária. Nesta perspectiva, património e identidade só são compatíveis quando se assume que o património funciona como uma espécie de luto em que o louvor do que morreu permite aos indivíduos constatar e tornar suportáveis as mudanças a que as identidades estão sujeitas. 
Olhar para a identidade como um recurso metonímico dos processos de patrimonialização leva-me a encarar o património como uma metalinguagem e uma invenção cultural. Porque, mais do que objectos ou bens, ele é representação de algo. Representa o que nos arriscamos a perder, estando esta perda subsumida em identidades reais ou imaginadas, mais ou menos modestas, mais ou menos espectaculares. Reactivados, reinventados e idealizados, os bens, as práticas e os signos que dão forma material ao património são retirados das vivências quotidianas para lhes serem devolvidos de um modo onde a encenação e a estilização são factores de indução de uma consciência identitária. A condição de afirmação desta consciência é o seu carácter metonímico; desde a parte que é tomada pelo todo ao invólucro que é tomado pelo conteúdo. Neste processo performativo, o passado está em permanente actualização. E o que ainda não passou, na voracidade das políticas de patrimonialização, é muitas vezes esquecido, apagado ou proscrito.

\section{Referências Bibliográficas}

Apor (2001), “Porto com pinta”. Página consultada em 14/3/2004. Disponível em http:/ /www.apor.pt/portopinta.php

Ashworth, G. J. (1994), "From History to Heritage — From Heritage to Identity. In Search of Concepts and Models", in Greg Ashworth; P. Larkham (orgs.), Building a New Heritage. Tourism, Culture and Identity in the New Europe. London/New York: Routledge, 13-30.

Cardoso, José Manuel (2002), “Comboios históricos no Douro até Outubro”, Jornal de Notícias, 4 de Março.

Choay, Françoise (1992), L'allégorie du patrimoine. Paris: Seuil.

Costa, José Manuel Aguiar Portela da (1999), Estudos cromáticos nas intervenções de conservação em centros históricos: bases para a sua aplicação à realidade portuguesa. Évora: Universidade de Évora (diss. de doutoramento).

FDZHP (1998), Manual do morador da zona histórica do Porto. Porto: Fundação para o Desenvolvimento da Zona Histórica do Porto.

Fortuna, Carlos (1999), Identidades, percursos, paisagens culturais: estudos sociológicos de cultura urbana. Lisboa: Celta.

Foucault, Michel (1977), Vigiar e punir: nascimento da prisão. Petrópolis: Vozes.

Frias, Aníbal; Peixoto, Paulo (2002), "Representação imaginária da cidade. Processos de racionalização e de estetização do património urbano de Coimbra”, Oficina do CES, 183.

Giedion, Siegfried (1990), Espace, temps, architecture. Paris: Denoël.

Giovannoni, Gustavo (1998), L'urbanisme face aux villes anciennes. Paris: Seuil. 
Guillaume, Marc (1980), La politique du patrimoine. Paris: Galilée.

Howard, Peter (2003), Heritage: Management, Interpretation, Identity. London/New York: Continuum.

IMPUQV (2003), "Institut Municipal del Paisatge Urbà i la Qualitat de Vida”. Página consultada em 23/5/2004. Disponível em http://www.bcn.es/paisatgeurba/

Lopes, Catarina Serra (2001), "Tipografia Confiança muitas vezes de portas fechadas”, Público, 21 de Outubro.

MacCannell, Dean (1973), "Staged Authenticity: Arrangements of Social Space in Tourist Settings", American Journal of Sociology, 79(3), 589-603.

Mendes, José Manuel (2001), "O desafio das identidades", in Boaventura de Sousa Santos (org.), Globalização. Fatalidade ou utopia?. Porto: Afrontamento, 489-523.

Mora, Alfonso Alvarez (1993), "La renovación de los centros urbanos como pratica ideológica”, Ciudades, 1, 19-35.

Osório, Ermelinda (2002), "Comboio a vapor pode ser cancelado", Jornal de Notícias, 7 de Julho.

Ostrowski, (1976), Les ensembles historiques et l'urbanisme. Paris: Centre de Recherche d'Urbanisme.

Peixoto, Paulo (2003), "Centros históricos e sustentabilidade cultural das cidades", Sociologia, 13, 211-226.

Público (2002a), "O regresso: velhos eléctricos voltam à rua”, Público, 4 de Maio.

Público (2002b), "Comboio histórico incendeia vinhas e quintas da Régua”, Público, 9 de Julho.

Ramalho, Maria Irene (2001), “A sogra de Rute ou intersexualidades”, in Boaventura de Sousa Santos (org.), Globalização: Fatalidade ou utopia?. Porto: Afrontamento, 525-555.

Vitalis, André (1998), "De la relation de discipline aux technologies de contrôle”, in Michèle Ansidei et al. (orgs.), Les risques urbains. Acteurs, systèmes de prévention. Paris: Anthropos, 173-183. 